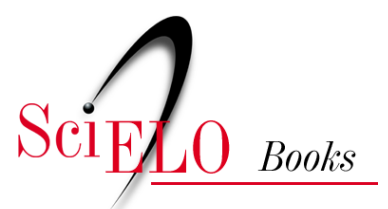

\title{
Comunicação e negociação gerencial
}

\author{
Francisco Javier Uribe Rivera
}

RIVERA, F.J.U Comunicação e negociação gerencial. In: Análise estratégica em saúde e gestão pela escuta [online]. Rio de Janeiro: Editora FIOCRUZ, 2013, pp. 219-244. ISBN: 978-85-7541-303-6. https://doi.org/10.7476/9788575413036.0007.

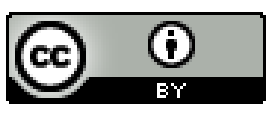

All the contents of this work, except where otherwise noted, is licensed under a Creative Commons Attribution 4.0 International license.

Todo o conteúdo deste trabalho, exceto quando houver ressalva, é publicado sob a licença Creative Commons Atribição 4.0. 
 \\ ComUnicaÇÃo e NEGOCIAÇÃo GERENCIAL}

$A$ necessidade de gerir organizações profissionais, entre as quais se situam as de saúde, obriga a pensar os termos comunicação e negociação como elementos decisivos de um determinado modelo de gestão. Usamos o termo organização profissional no sentido dado por Mintzberg (1982), como característico de um tipo organizacional dominado, do ponto de vista da possibilidade de controle dos processos de trabalho e das decisões administrativas, pelos centros operadores (com uma grande dose de autonomia destes), e em que a padronização produtiva e as formas de coordenação são dependentes, em boa parte, de conhecimentos, habilidades e formas de status adquiridos fora da organização nas associações respectivas e nas universidades.

Em trabalho anterior (Rivera, 1995), analisando as características dessas organizações, tais como a não-padronização absoluta de muitas relações de insumo-produto e a imprecisão de seus resultados, afastamos a possibilidade de uma gerência tradicional, de uma normatização "mecanística" de processos.

Considerando: a) o envolvimento em uma malha intrincada e variável de uma ampla gama de serviços e de categorias profissionais, vinculados a processos em permanente diversificação; b) o corporativismo dessas categorias que conspira contra a idéia de equipe, tão cara à prestação de serviços sanitários; c) a necessidade de definir coletivamente mecanismos de avaliação de resultados (e de responsabilidades); d) o caráter interativo do trabalho finalístico etc., aderimos a um tipo de modelo de gestão comunicativo, negociativo, consensual.

O entendimento da administração pública como uma arena de interesses variados de atores, em disputa por uma dada hegemonia, reforça, ainda, a idéia de aprimorar a comunicação interna como meio para a cristalização de pactos normativos capazes de coerir essas organizações. A característica básica do poder nas organizações profissionais, não concentrado, mas fortemente comparti- 
lhado ou distribuído pelos vários centros operadores e núcleos profissionais e operativos, reforça um sistema de gestão que tem no ajustamento mútuo e na negociação de interesses um dos seus traços marcantes.

Nesse contexto, a necessidade de uma discussão sobre formas de aprimoramento da comunicação e da capacidade de negociação dos agentes organizacionais adquire uma clara relevância.

Apresentamos, aqui, algumas das bases do modelo de negociação da Harvard Law School e avançamos algumas possibilidade de complementação do mesmo a partir de enfoques lingüísticos ou comunicativos. Precedemos esta análise de uma revisão concisa das formas de negociação e de negociador, pois essa análise ajuda a melhor circunscrever o tipo específico de modelo que sustentamos.

\section{Tipos de Negociação e de Negociador}

Matus (1994) distingue três tipos de negociação:

- Cooperativa: baseada em interesses distintos e objetivos comuns, dando lugar a um jogo de soma positiva.

- Conflitiva, baseada em interesses opostos, dando lugar a um jogo de soma 0.

- Mista, baseada em interesses opostos combinados com interesses distintos, dando lugar a uma negociação mista.

Para este autor, a escolha do tipo de negociação vem determinada pelo tipo de objeto da negociação. Assim, por exemplo, as questões envolvendo uma comunidade econômica suscitam, em geral, formas de negociação mistas; as cooperativas econômicas são mais afetas a formas cooperativas de negociação; e finalmente, a negociação da compra de um imóvel envolve formas mais conflitivas, onde guardar segredo sobre informação vital é uma estratégia natural.

É importante que se diga que Matus situa a negociação como uma possibilidade de meio estratégico, ao lado da autoridade, da persuasão e do conflito.

Chalvin (1997) distingue a negociação do entendimento e da autoridade. A autoridade corresponderia, como defende Matus, à imposição hierárquica de diretrizes, pressupondo a legitimidade da hierarquia e poderes desiguais. A autoridade poderia, no entanto, deslizar para a violência coercitiva. $O$ entendimento suporia poderes iguais e uma comunidade absoluta de interesses. Para este autor, a negociação comportaria um processo crítico de articulação de poderes diferentes e complementares, com base na tolerância e na pluralidade. Situada entre a autoridade e o entendimento natural, a negociação tipifica um universo de poder flutuante. 
Chalvin identifica vários enfoques de negociação:

- O enfoque persuasivo: o negociador aqui preza a competição e as negociações difíceis. Defende seu ponto de vista com força, gosta de ganhar. Estabelece prazos para a negociação, seu discurso é avassalador visando a reduzir o outro. Sempre pede mais para obter um pouco menos. Há, neste caso, um sentido de manipulação. Este estilo pode comprometer claramente a relação interpessoal envolvida na negociação.

- O enfoque cooperativo: o negociador pertinente se preocupa com seu interlocutor e busca encontrar um objetivo comum, elaborando em conjunto uma solução nova. É o jogo do tipo ganhar-ganhar. Há uma opção pela comunicação, em detrimento da agressividade e da disputa. Há a predisposição a compartilhar o poder. A preservação da relação é o objetivo supremo, podendo até comprometer até a obtenção de ganhos.

- O enfoque considerado ideal: nesta alternativa, persegue-se a resolução de problemas, a adesão completa das duas partes a uma alternativa de solução duradoura, construída ao longo de uma discussão profunda. Esta opção dificilmente se diferencia da anterior, a não ser pela idealização de uma solução perfeita, que implique o máximo de ganho e de relação, possibilidades às vezes conflitantes.

- O enfoque pela conciliação: é um estilo adaptativo, lento, realista, de soma progressiva de interesses, na linha dos arranjos provisórios. É um estilo camaleônico de articulação preocupado com a obtenção de pequenos resultados. Trata-se de uma política pragmática de resultados, que não produz soluções perfeitas e duradouras.

- O enfoque procedural: corresponde a um enfoque burocrático, ritualístico, de produção de acordos basicamente formais, versando sobre procedimentos e não sobre conteúdos substantivos.

Para este autor, o que existe, na prática, é uma combinação de enfoques de negociação, com alguns apresentando uma maior capacidade de convergência. Da mesma maneira, assim como em Matus, o autor sustenta que é necessário dosar ou combinar, de maneira adequada à realidade, as estratégias maiores de autoridade, entendimento e negociação.

Zajdsznajder (1988) estabelece uma discussão sumamente interessante sobre duas formas básicas de negociação: a negociação baseada na argumentação e aquela baseada na persuasão. Para ele, a base da argumentação é a comunicação crítica. Esta implicaria a apresentação de razões ou de uma base de prova para as teses defendidas e na obtenção de um convencimento legítimo em relações a estas razões, que poderão ser sucessivas. 
Na persuasão, haveria um tipo de convencimento não crítico, não baseado em razões. O acordo poderia ser obtido com base na adesão pura e simples de uma parte a um político poderoso capaz de oferecer segurança; com base em um discurso agressivo ou manipulador, hipnótico, que se adapta a cada público; e com base na exploração das emoções. Esta caracterização coincide com a de Matus, que diferencia a negociação da persuasão tendo em vista que, na primeira, haveria a disposição de fazer concessões, ao passo que, segunda haveria uma total cooptação.

O modelo escolhido como opção mais promissora, neste trabalho, é o da negociação cooperativa que visa, dentro do possível, ao ideal, e este modelo estaria baseado prioritariamente na argumentação crítica. O modelo de Negociação de Harvard estaria situado nesta faixa. Na linha de Zapiola (1992), uma ressalva importante a ser feita ao método está relacionada à sua denominação: Como Chegar ao Sim - a Negociação de Acordos sem Concessões. Um método argumentativo do tipo ganhar-ganhar não comportaria a não realização de concessões como sua característica.

Considera-se, aqui, a inevitabilidade de uma interação argumentativa-persuasiva, tal como reconhecida por Zajdsznajder. Preconiza-se a subordinação de um componente persuasivo da negociação, difícil de afastar, à argumentação crítica. E, por fim, sustenta-se a idéia de que a determinação da situação em jogo sobre o tipo de enfoque negociativo não é absoluta, de modo a podermos priorizar voluntariamente a busca permanente de um ideal de enfoque cooperativo.

\section{O Modelo de Negociação de Harvard Revisitado}

Este modelo, consubstanciado em Como Chegar ao Sim - a Negociação de Acordos sem Concessões (Fisher \& Ury, 1985) e em Como Chegar a um Acordo (Fisher/ Brown; 1990), também é conhecido como o método de negociação a partir de princípios ou em função do mérito. É visto como uma alternativa à negociação suave, em que o negociador, para evitar o conflito, limita-se a concessões unilaterais, e/ou à negociação áspera, em que o negociador acirra o conflito defendendo posições extremas na expectativa de derrotar o interlocutor.

O modelo consta de quatro elementos básicos:

- Separar o relacionamento da substância do problema, trabalhando o relacionamento interpessoal como um interesse particular do processo de negociação.

- Negociar a partir dos interesses e não de posições. 
- Buscar opções variadas de ganho mútuo através de um processo criativo.

- Negociar antes de mais nada os princípios ou padrões objetivos a partir dos quais a negociação pode ser possível.

\section{A questão do relacionamento}

Trabalhar o aspecto do relacionamento interpessoal implica prestar atenção a três dimensões: a percepção, a emoção e a comunicação.

Em relação à percepção, o método faz uma série de recomendações, que relacionaremos a seguir:

- Considerando que a percepção é situacional, que não há verdade absoluta, que tendemos a ver aquilo que queremos ver em função de nossa tradição, é indispensável tentar ver como o outro vê. Isto implica colocar-se no lugar do outro. O marco do "como se" é uma técnica necessária: como veríamos uma dada situação se estivéssemos no lugar do outro?

- É importante procurar não deduzir as intenções dos outros de nossos próprios medos. Isto significa a necessidade de não atribuir a priori a pior das interpretações ao que o outro lado diz ou faz. Este tipo de "cegueira situacional" pode levar a desprezar idéias novas e interessantes no sentido de um acordo e a ignorar mudanças sutis de posição.

- É fundamental não culpar o outro por seu problema. A atribuição direta de culpa, mesmo que justificada, é geralmente contraproducente. Aqui há um problema de saber comunicar. A título de ilustração, há uma diferença entre os dois seguintes enunciados: (a) "Sua companhia é totalmente indigna de confiança. Todas as vezes que vocês fazem a manutenção de nosso gerador giratório aqui na fábrica, fazem um trabalho de péssima qualidade e ele torna a quebrar"; e, (b) "Nosso gerador giratório, cuja manutenção vocês costumam fazer, voltou a quebrar. Isto soma três vezes no mês passado. $\mathrm{Na}$ primeira vez, ficou enguiçado por uma semana inteira. A fábrica precisa de um gerador que funcione. Quero sua opinião sobre como podemos minimizar nosso risco de falhas no gerador. Será que devemos mudar de empresa de manutenção, ou o que vocês sugerem". Atribuir culpa enreda firmemente as pessoas com o problema, gera uma resistência no plano interpessoal que compromete a negociação do problema. É claro que o segundo enunciado é bem mais positivo.

- É importante considerar todas as percepções do outro lado, de cada um. Alguns interesses tratados como sem importância, no sentido de não se tornarem em obstáculos a um acordo, podem, se bem explorados, criar áreas de afinidade ou de acordo capazes de ajudar a um acerto mais geral. 
- Agir, em determinadas oportunidades, de maneira contraditória às percepções do outro, pode contribuir para aparar arestas e abrir espaços para acordos. A inesperada visita de Anwar Sadat, presidente do Egito, a Jerusalém, em 1977, é um bom exemplo disto. Em vez de agir como aquele inimigo declarado, Sadat age como um parceiro. Este passo dramático contribuiu, sem dúvida, para a assinatura de um tratado de paz entre Egito e Israel.

- A realização de qualquer acordo subentende a participação do outro desde o início do processo. É importante dar-lhe um interesse no resultado, certificando-se de que ele participa do processo. Por exemplo, grande parte da legislação anti-apartheid, formulada apenas por legisladores brancos, caiu no descrédito, porque estas medidas foram entendidas pelos negros como mais uma afirmação da "opressão do homem branco". A melhor maneira de caracterizar esta recomendação é assumir que o processo em si é o real produto da negociação.

- É fundamental, ainda, preparar os termos de um acordo, sobretudo daquele que implica desvantagens para o outro, de maneira tal que não violente os valores, os princípios e a auto-imagem dos outros negociadores. Redigir a substância do acordo de modo tal que o resultado pareça justo ajudará à posição dos outros, à defesa dessa posição perante eventuais cobranças das autoridades superiores. Isto corresponde ao conselho: "salvar as aparências: torne suas propostas compatíveis com os valores do outro". Tal preocupação fortalece a possibilidade de um relacionamento futuro positivo.

Em relação ao aspecto emoção, o método, além de destacar a importância crucial dos sentimentos relativamente as próprias palavras, no sentido de poderem comprometer significativamente o processo de acordo, aconselha a absoluta transparência.

Explicitar as emoções e reconhecer sua legitimidade é absolutamente normal e necessário. Libertar-se do fardo das emoções não exprimidas aumenta significativamente a probabilidade de as pessoas trabalharem no problema. Isto subentende a necessidade de deixar que o outro desabafe, de criar um clima que propicie isto. Uma regra de ouro se aplica aos casos de reação agressiva: escutar em silêncio, não reagir, pedir que o outro prossiga; somente uma pessoa teria o direito de se zangar de cada vez.

A utilização de gestos simbólicos que expressem carinho, solidariedade, preocupações pelo outro, minoram as possibilidade de um clima hostil.

Em situações de um estado emocional negativo, a utilização de técnicas de visualização pode ser útil. Colocar-se em "estado de recurso" corresponde a visualizar cenas de negociação do passado em que estivemos plenamente realizados, motivados, envolvidos em processos positivos. Da mesma maneira, poderíamos 
concentrar-nos no estado emocional em que gostaríamos que nosso parceiro estivesse e adotar este estado. O outro pode seguir o nosso exemplo, contagiarse, buscar recursos positivos.

Uma variante da técnica do "como se" é a dissociação visual-cinestésica. Aplica-se a situações em que o parceiro da negociação está encurralado em um estado interno negativo ou processo de autoconvicção negativa, fechado em posições, sem poder avançar. A idéia implícita é desconectar o parceiro desse estado de concentração em sentimentos e diálogos internos, no nível da representação cinestésica, através do recurso da visualização. Considera-se que colocar o interlocutor como observador da situação, mudando sua forma de representação sensorial, é uma forma de mudar seu estado. Esta sorte de desvio da atenção permitiria à pessoa tomar distância em relação a seu problema - assumir uma metaposição. Pedir para que a pessoa envolvida imagine o que veria na situação que está vivendo se estivesse no lugar de outrem é uma forma de recurso. Em geral, trata-se de formular perguntas que façam com que aquela pessoa olhe a situação, diga o que vê realmente. Explorar a representação visual do objetivo dessa pessoa, induzi-la a fazer uma imagem construída do mesmo, insere-se nessa lógica que opera como técnica simples de criatividade. Isto corresponde em geral a assumir o outro não como um inimigo, mas como parceiro, sócio do processo de negociação.

O aspecto da comunicação é o terceiro elemento do trabalho voltado sobre a relação. Sem comunicação não há negociação. Haveria três grandes problemas de comunicação:

- Não falar para o outro interlocutor, mas para uma platéia.

- Não escutar, por estar concentrado nos lances de pensamentos futuro.

- Os mal-entendidos da comunicação, considerando compreensões diferentes de termos (por motivos culturais) ou um tipo de comunicação discursiva, indireta, imprecisa.

As recomendações pertinentes são as seguintes:

- Escutar e registrar ativamente o que esta sendo dito. Perguntar, solicitar esclarecimentos diante de ambigüidades é fundamental, assim como reproduzir positivamente, de maneira resumida, os termos da colocação do outro. O outro, ao se aperceber que sua proposta está sendo entendida, ficará muito satisfeito. $\mathrm{O}$ ideal é reproduzir a proposta do outro em melhores termos do que a formulação originária. Ajudar a precisá-la melhor. Nesta operação, não se emitiriam julgamentos, comentários críticos. Fica extremamente mais fácil, posteriormente, questionar a colocação do outro, quando se obtém um acordo inicial construtivo sobre o que o outro está querendo dizer. A utilização dos mesmos predicados que o outro emprega cria 
uma sintonia fina, um rapport, uma aproximação quase que "fisiológica". O back tracking ou reprodução resumida da proposta do outro utilizando o tipo de predicados por ele utilizados é uma técnica bastante utilizada no campo da psicologia, ajudando a harmonizar, a comunicar. A Psicologia Comportamental parte da hipótese de que, na representação sensorial da experiência, as pessoas utilizam predominantemente uma determinada forma de representação, que é o sistema sensorial que estaria sob o foco da conscientização. Assim, fala em pessoas predominantemente visuais ou auditivas ou cinestésicas. A linguagem dos seres humanos refletiria essa predominância. As pessoas visuais utilizariam predominantemente ou muitos predicados visuais (à primeira vista, esclarecer, ilustrar, visivelmente, evidentemente, etc.) e assim por diante. Estes tipos apresentariam, ainda, determinadas características de comportamento não-verbal ou uma determinada fisiologia. Os cinestésicos, ilustrando, teriam uma respiração profunda, ampla; seus movimentos mimetizariam as palavras; a voz seria grave, o ritmo lento com muitas pausas etc. Esta construção é utilizada em vendas. Procurar vender um produto pelas suas qualidades visuais a uma pessoa cinestésica é uma péssima estratégia. Uma pessoa deste tipo poderia ficar sensibilizada por qualidades como a textura, o conforto etc. A aplicação desta técnica ao campo da negociação é óbvia. Convencer fica mais fácil se utilizarmos o tipo de predicados adequados à forma de representação primária do parceiro da negociação. Portanto, é absolutamente necessário traduzir nossos argumentos na linguagem do outro. Esta técnica pode ser reforçada pelo espelhamento que implica refletir o comportamento não verbal dos participantes de uma negociação de modo a criar uma sintonia, uma aproximação inconsciente (voz, gestos, postura, respiração etc.). Além de ajudar a criar uma relação mais harmoniosa, o espelhamento é considerado um instrumento que precede à possibilidade de conduzir o parceiro (leading).

- É importante falar para ser entendido. Recomenda-se empregar meios privados e confidenciais de comunicação, grupos relativamente pequenos, para evitar a situação de ter de afirmar-se diante de terceiros, e utilizar uma comunicação direta, concisa, não excessiva. Isto subentende falar com objetivos claros, saber o que se quer comunicar.

- Fale sobre você e não sobre o outro. Condenar as motivações do outro leva a inevitáveis questionamentos. É mais conveniente descrever o impacto de um problema sobre você do que analisar o problema do ponto de vista da responsabilidade do outro. Dizer: 'sentimo-nos discriminados', em lugar de 'você é racista' faz uma grande diferença. 


\section{Negociar interesses e não posições}

O segundo passo decisivo do modelo em pauta consiste em evitar a barganha posicional, pois esta põe em conflito a relação com a substância do problema. Concentrar-se nas posições ou nas respostas específicas que você quer obter, de maneira egocêntrica, leva a situações extremadas, de estrangulamento (da própria relação). Antes disso, é necessário conciliar interesses, enquanto os fundamentos (ou causas) de uma posição (desejos, necessidades, temores, valores).

Fisher \& Ertel (1997) demonstram a diferença entre posições e interesses. Se estamos inseguros sobre se algo é uma posição ou um interesse, devemos determinar se há mais de uma maneira de satisfazê-lo. Se não houver, como no caso de 'eu exijo um carro da empresa', trata-se de uma posição. Em contrapartida, se houver várias maneiras de satisfazer uma exigência (como no caso de ‘quero transporte para o trabalho' ou 'quero mais status na empresa'), é provável que seja um interesse.

Para descortinar os interesses subjacentes, é necessário aplicar a si próprio e/ou ao interlocutor a técnica do por quê: por que o outro assume uma dada posição ou por que o interlocutor não assumiria uma determinada posição? (que seria aquela que corresponde à posição que nós esperaríamos ou gostaríamos que ele tomasse). As decisões ou motivações oriundas do uso sistemático do por quê podem ser hierarquizadas, através de perguntas sucessivas que vão descortinando novas motivações envolvidas nas primeiras a aparecer. As últimas motivações em geral são as mais decisivas.

Em alguns modelos de negociação (Kluczny, 1993), mais ligados à mediação, à arbitragem, o ponto de partida consiste na definição de um meta-objetivo que una as partes, de um objetivo compartilhado, do que se denomina a base de resultados de um acordo.

Este ponto pressupõe que ambas as partes definam seu objetivo no processo de negociação. A definição do meta-objetivo comum resulta de perguntar a cada parte o benefício a ser alcançado com o objetivo específico. Sucessivas perguntas no sentido de 'para que finalidade'? podem levar à definição da chamada base de resultados.

Em geral, os meta-objetivos correspondem lingüisticamente a nominalizações. As nominalizações são palavras que entram no lugar de um substantivo na sentença, mas não podem ser tocadas, sentidas, nem ouvidas. Não são tangíveis. Palavras como amor, felicidade, curiosidade são exemplos. São palavras abstratas, genéricas, sem especificidade em termos de conteúdo. Prestam-se subjetivamente a múltiplas interpretações e não suscitam oposição. Por isso facilitam acordos gerais. São fenômenos lingüísticos que transformam um processo dinâmico em um acontecimento abstrato, coagulado (amar em amor, por exemplo). 
Estes fenômenos nos impedem de saber o conteúdo concreto, a forma concreta do acontecer de tal acontecimento. Nesta medida, são considerados fenômenos de distorção da experiência ou de substituição de dados sensoriais.

Dado um determinado meta-objetivo e definidas algumas condições básicas para que se decida no processo negociativo, preconiza-se a aplicação sistemática da técnica do "desafio de relevâncias". Isto corresponde a lembrar, o tempo todo, em que medida uma determinada discussão é relevante do ponto de vista da base de resultados da negociação. Desta maneira, economiza-se tempo, evitam-se caminhos colaterais e se organiza o processo de alcançar objetivos concretos.

A premissa implícita na possibilidade de negociar interesses é a de que por trás de posições opostas, além de interesses conflitantes, haveria interesses comuns e interesses diferentes, não necessariamente incompatíveis.

A idéia seria, então, ampliar a faixa de acordo em torno dos interesses comuns e em explorar em profundidade a possibilidade de conciliar ou harmonizar os diferentes, de modo a criar formas de afinidade que aplainem o caminho para uma negociação mais geral. É necessário considerar, ainda, que um mesmo lado pode ter interesses múltiplos, oferecendo a possibilidade de acordos com segmentos desse lado. Algumas necessidades humanas básicas podem ser consideradas interesses, como: a segurança, o bem-estar econômico, o sentimento de pertença, o reconhecimento, o controle sobre a própria vida.

A título de ilustração, citamos o tratado de paz egípcio-israelense esboçado em Camp David em 1978. Israel tinha ocupado a península do Sinai na Guerra dos 6 dias em 1967 e não abria mão de uma parte do Sinai. O Egito queria a devolução completa. Por inúmeras vezes, as duas partes insistiam em suas posições de maneira recalcitrante. Mapas e mapas mostrando possíveis fronteiras eram desenhados dividindo o Sinai, sem sucesso. A análise dos interesses possibilitou o acordo. Israel queria a segurança, não queria tanques egípcios na sua fronteira. O Egito queria a soberania, tendo em vista que, depois de anos de ocupação colonial por sucessivos povos, essa república tinha conquistado sua soberania total, valor político inestimável para sua população. Sadat e Begin concordaram com um plano que restituiria o Sinai à soberania egípcia e que desmilitarizaria amplas áreas, garantindo a segurança de Israel. A bandeira egípcia tremularia em todo o território, mas não haveria tanques egípcios perto da fronteira israelense.

Outra situação que se presta a uma ilustração das possibilidades de negociação de interesses, para além da barganha posicional, é a negociação do preço do aluguel de um imóvel. Haveria aqui interesses conflitantes. Maximizar/minimizar o preço do aluguel. A possibilidade de um acordo sobre o problema iria depender muito da negociação com base em outros interesses. Haveria exem- 
plos de interesses comuns, a explorar: ambos querem estabilidade (uma relação de inquilinato duradoura); ambos gostariam que o imóvel fosse bem conservado; ambos poderiam ter um interesse num bom relacionamento mútuo. É possível que elas tenham interesses não conflitantes, mas simplesmente diferentes, por exemplo: o inquilino talvez não queira lidar com tinta fresca e o proprietário não queira arcar com o custo da pintura; o proprietário gostaria de segurança de um pagamento antecipado pelo primeiro mês de aluguel e talvez queira recebêlo amanhã, ao passo que o inquilino, sabendo que o apartamento vale a pena, talvez não se importe com esse tipo de condição de pagamento. Os interesses conflitantes talvez possam ser melhor contornados, se houver acordo em relação a interesses comuns e divergentes. Por exemplo, a disposição do inquilino de arcar com o custo da tinta, caso o proprietário se disponha a assumir a pintura, junto com a aceitação, por parte do inquilino, de um pagamento antecipado. Eles podem se colocar de acordo, antes de mais nada, em relação à necessidade de uma boa conservação do imóvel, admitindo um esforço compartilhado, e à necessidade de cultivar um bom relacionamento futuro.

Em relação a este passo, a transparência é um imperativo. É necessário dar vida aos interesses, ser explícito. $\mathrm{O}$ ato de declinar dos interesses próprios deve ser acompanhado da busca de seu reconhecimento por parte do outro. Dar legitimidade aos próprios interesses é uma busca permanente e necessária, acima de tudo quando aqueles são considerados extremamente pertinentes. $\mathrm{O}$ reconhecimento dos interesses do outro como parte do problema é o avesso da situação anterior. Reconhecer os interesses do outro explicitamente, pode ser o primeiro passo para o reconhecimento dos próprios. O relato ou o reconhecimento dos interesses do outro pode ser precedido do enunciado 'corrija-me se eu estiver errado', o que já caracteriza uma posição de abertura. Se o outro não corrigir o relato de suas motivações, implica que ele aceita sua descrição da situação. É mais uma área de acordo. Mais uma forma de "fisiologia do sim".

Algumas outras algumas recomendações são interessantes.

- Colocar o problema antes da solução. No caso de uma obra de construção, cujos caminhões põem em risco a vida das crianças da localidade, a melhor forma de comunicar não seria, por exemplo: 'creio que vocês deveriam levantar uma cerca em torno da área do projeto dentro de 48 horas e limitar, imediatamente, a velocidade de seus caminhões a 25 quilômetros por hora. E lhe digo por quê.' Desta maneira, o interlocutor seguramente não escutará suas razões. Falar primeiro dos riscos para as crianças pequenas, fazendo com que o construtor se coloque na sua situação, reconhecendo o valor da vida humana, é uma forma mais efetiva de promover uma escuta construtiva. 
- Esquecer situações negativas do passado e concentrar-se no futuro ajuda a criar um relacionamento mais construtivo, assim como reenquadrar o passado, procurando e comunicando os aspectos positivos de situações de negociação anteriores de caráter crítico.

- Ter uma mente aberta a várias opções e não a uma única é outro imperativo óbvio.

- Ser rigoroso com o problema e afável com as pessoas cria o fenômeno da "dissonância cognitiva", segundo o qual as pessoas tendem a eliminar a incoerência - de efeitos desagradáveis - promovendo uma tendência para o acoplamento.

\section{Buscar opções criativas de ganho mútuo}

O terceiro passo do método se refere à necessidade de buscar primeiro soluções criativas e depois decidir (de não confundir o processo da invenção com a decisão mesma).

Haveria uma série de obstáculos à criatividade necessária à negociação:

- O julgamento crítico, prematuro, exacerbado, mata a criação, a imaginação.

- As pessoas acham que sua tarefa é estreitar o hiato entre as posições e não ampliar as opções disponíveis. Isto corresponde à busca de uma resposta única.

- Há, em geral, a pressuposição equívoca de um bolo fixo. A história da divisão da laranja, de duas crianças que disputam a mesma laranja e que concordam em parti-la ao meio, uma usando apenas a casca e jogando fora o sumo e a outra fazendo o contrário, desmistifica a idéia de que toda negociação é um processo que supõe um bolo fixo (que implica soluções do tipo ganhar/perder).

- Predomina, às vezes, a idéia de que 'resolver o problema dos outros é problema deles'. A abordagem unilateral do problema da negociação é outro obstáculo à possibilidade de opções várias de ganhos mútuos. Essa abordagem leva ao fechamento egocêntrico, reforça o segundo obstáculo, compromete a possibilidade da diversidade.

Diante deste quadro de obstáculos, surgem algumas recomendações:

\section{Separar a invenção das decisões}

A realização de sessões de sugestões livres (brainstorming session) ao interior do ator que negocia e/ou junto com os interlocutores é o método básico para 
estimular a criatividade. Algumas regras se impõem: mudar o ambiente da sessão; criar uma atmosfera informal; escolher um facilitador que garanta a simetria e a riqueza do debate; trabalhar com grupos nem muito grandes, para estimular a participação individual, nem muito pequenos, para proporcionar um intercâmbio estimulante; fazer com que os participantes sentem-se lado a lado (semicírculo), enfrentando o problema (delineado em um quadro), pois o físico reforça o psicológico, no caso, a busca cooperativa de opções; esclarecer as regras básicas, especialmente a regra da proscrição de críticas negativas; sugerir livremente; registrar as idéias a vista de todos, reforçando o sentimento de construção coletiva. A partir daí, sugere-se não cumprir à risca a regra da ausência de críticas, assinalando as idéias mais promissoras, tomar uma idéia promissora e aperfeiçoá-la e estipular um prazo para avaliar as idéias e decidir. Para "quebrar o gelo" em uma reunião com os interlocutores, é muito útil assumir o hábito de propor pelo menos duas alternativas ao mesmo tempo, para não criar a impressão do comprometimento com uma única idéia, ou apresentar antes do relato de alternativas de opções, idéias contraditórias das quais você visivelmente discorda.

\section{Ampliar as opções é essencial}

Ampliar as opções sugere uma metodologia que corresponde a um deslocamento das opções entre o particular e o geral. O ponto de partida consistiria em procurar processar (descrever e explicar) um problema e possíveis alternativas de solução. Neste ponto, pode tentar-se uma extrapolação que signifique identificar a abordagem geral ou a teoria geral que subjazem a uma idéia particular (uma opção) ou à própria explicação do problema. A seguir, procurar-se-ia discutir outras alternativas inerentes à mesma forma de abordagem geral. Uma boa forma de estimular a criatividade é observar problemas e propostas através do olho de diferentes especialistas.

Uma técnica de dissociação do interlocutor pode ser tentada, visando a demovê-lo de afirmações categóricas, expressas de maneira muito firme a respeito de alguma coisa. Aplica-se a situações críticas em que o interlocutor se prende a formulações fixas de caráter negativo. A lógica desta técnica consistiria em assumirmos novos papéis, através de uma simulação baseada na pergunta: 'O que eu pensaria desta questão caso fosse....?'. As novas dimensões positivas decorrentes dos novos papéis assumidos seriam introduzidas de surpresa no diálogo, de modo a ajudar a fixar a associação desta ou daquela dimensão (o elemento surpresa operaria como âncora). Estima-se que uma tendência natural das pessoas de fugir das situações desagradáveis atuaria como facilitador deste processo de ampliação de opções ou de reenquadramento positivo da situação, que não deixa de ser uma auto simulação de um encontro multidisciplinar. 
A relação de opções possíveis pode aumentar se forem consideradas 'versões mais leves' de enfrentamento de problemas, caso o acordo buscado venha revelar-se inatingível. A recomendação implícita é buscar acordos de pesos diferentes. Se vocês não puderem concordar quanto à substância, talvez concordem quanto ao procedimento (por exemplo, a necessidade de uma arbitragem). Do mesmo modo quando um acordo permanente não é possível, talvez um acordo provisório o seja. Se não for possível chegar a um acordo de primeira linha, talvez seja possível um acordo de segunda linha - concordando sobre o que discordam.

O condicional close ou moldura do "como se" pode ter uma utilidade na definição de acordos de pesos diferentes. Esta técnica se aplica a situações em que há objeções que dificultam o acordo. A idéia é procurar um acordo condicionado que pode ser sucessivo. Pergunta-se, à parte que objeta, se concordaria com uma dada proposta, caso as objeções que exprime fossem atendidas ou equacionadas. O objetivo é reforçar a "fisiologia do sim", pois esta facilita um acordo.

Modificar o alcance de acordo proposto, parcializando ou recortando a substância do problema, pode ensejar, ainda, acordos parciais, envolvendo um menor número de partes ou cobrindo apenas alguns aspectos.

\section{Procurar ganhos mútuos}

Esta questão está diretamente ligada com o passo 2 do método, que preconiza explorar os interesses comuns e harmonizar os diferentes (não incompatíveis). Chegar a um acordo através das diferenças subentende a existência de interesses que podem ser harmonizados. Isto pode ficar claro se considerarmos que há situações em que:

Um parte importa-se mais com:

- a forma

- as considerações econômicas

- o futuro imediato

- o precedente

- o prestígio, a reputação

- o equipamento pesado
A outra parte importa-se mais com:

- a substância

- as considerações políticas

- o futuro mais distante

- este caso

- os resultados

- a ideologia etc. 
A existência de crenças diferentes pode ser aproveitada, por exemplo, para convocar uma arbitragem. A valorização diferente do tempo entre vendedor e comprador possibilita acordos que impliquem planos de financiamento. O comprador paga mais caro pelo carro, se puder pagar mais tarde. $\mathrm{O}$ vendedor se dispõe a acertar um pagamento posterior, se puder obter um preço maior. $\mathrm{E}$ assim, há diversas situações de diferença que, ao invés de afastar, podem ser capitalizadas em termos de um acordo baseado na análise de interesses.

\section{Facilitar a decisão do outro}

Facilitar a decisão do outro se inscreve, na mesma linha de raciocínio da máxima: salvar as aparências do acordo. Mas também quer dizer que a negociação deve evitar o espírito de manipulação dos acréscimos deliberados com a finalidade de "criar mais espaço de negociação" e que deve considerar as conseqüências de um acordo x para o outro, procurando melhorá-las.

\section{Definir padrões para a negociação}

O quarto passo decisivo consiste em buscar, em insistir em critérios objetivos, em acertar padrões justos e independentes da vontade que podem balizar um acordo. O ponto de partida da negociação deveria ser este acerto. Entre estes padrões, podemos citar vários: o valor de mercado, o precedente, a opinião científica, os custos, um tribunal, padrões morais, a tradição etc. A busca por critérios justos pode referir-se a um conjunto de padrões que ajudem a dirimir a questão substantiva ou a procedimentos justos para resolver os interesses conflitantes. A antiqǘssima forma de dividir um pedaço de bolo entre duas crianças: uma corta e outra escolhe, é um exemplo de procedimento.

Uma variação da técnica do "um corta, o outro escolhe" consiste nas partes negociarem o que acreditam ser um acerto justo antes de decidir seus respectivos papéis. Isto se aplica aos casos de divórcio. Fazer revezamentos, tirar a sorte, deixar a decisão a cargo de um terceiro são outros exemplos interessantes. $\mathrm{O}$ importante é salientar que o ponto de partida é formular cada questão como a busca de critérios objetivos e buscar o acordo em torno deles.

Às vezes, um padrão de legitimidade não exclui a existência de outros. É importante considerar os padrões sugeridos pelo sócio da negociação e, por que não, eventualmente assumi-los. A melhor maneira de dirimir diferenças sobre o melhor critério é envolver mais pessoas, identificar qual é o padrão de maior aceitação social. Soluções de compromisso ou de divisão da diferença são acon- 
selháveis quando há dois critérios diferentes (preço de mercado e custo depreciado). O padrão usado pelas partes no passado pode ser, ainda, uma alternativa de resolução de diferenças.

Concluiremos esta parte fazendo alguns comentários rápidos (a partir de Como Chegar ao Sim) sobre como negociar com quem não quer jogar dentro das regras da negociação por princípios. O 'jiu-jitsu’ da negociação é uma forma de abordagem que se aplica nesses casos e que consiste em evitar jogar sua força diretamente contra a dele, usando de habilidade para esquivar-se (dos ataques) e direcionar a força do outro no sentido que lhe interesse. O objetivo é tentar trazer o outro para o campo da exploração dos interesses. As regras básicas dessa abordagem seriam:

- Não contra-atacar.

- Não atacar a posição do outro. É melhor aceitá-la como uma opção, procurando os interesses e princípios subjacentes e pensar em meios de aprimorá-los. Portanto, sempre olhe atrás da posição do outro.

- Faça com que o outro discuta hipoteticamente as conseqüências para nós da imposição de uma proposta defendida por ele. Não defenda suas idéias. Peça ao outro críticas e conselhos sobre uma idéia sustentada por você. Em vez de pedir-lhe que aceite ou rejeite uma idéia, pergunte-lhe o que há de errado nela: 'Qual de seus interesses esta proposta deixaria de levar em conta?'. Examine os julgamentos negativos do outro para descobrir-lhe os interesses subjacentes e aprimorar suas idéias desde o ponto de vista dele. Reelabore suas idéias à luz do que descobrir com ele, fazendo com que a crítica, antes um obstáculo ao processo de trabalhar pela obtenção de um acordo, transforme-se em um ingrediente essencial desse processo.

- Coloque o outro na sua posição e pergunte o que ele faria neste caso. É uma forma de canalizar críticas num sentido construtivo.

- Reformule os ataques a você como ataque ao problema. Exemplo: 'Quando o senhor diz que a greve demonstra que não nos importamos com as crianças, ouço nisso seu interesse pela educação das crianças. Compartilhamos desse interesse, elas são nossos filhos. Queremos que a greve termine e possamos voltar a educá-las. Que podemos fazer juntos'.

- As pessoas empenhadas nessa abordagem usam dois instrumentos-chave: a pergunta e o silêncio. As afirmações geram resistências, ao passo que as perguntas geram respostas. Elas, ademais de ajudarem a discernir melhor os interesses dos outros, distendem o ambiente (minoram o conflito) e ajudam a criatividade. O silêncio provoca um desconforto no outro, especialmente quanto este tem dúvidas. Leva à necessidade de falar mais, de completar afirmações que culminaram em um impasse. Gera desafios. 
É importante citar que, mais recentemente, Ury aprofunda esta estratégia (1991). Neste trabalho, o autor reafirma a necessidade de procurar trazer o interlocutor para o campo da discussão de interesses ou para a postura de solucionar problemas (desviando-o da postura ofensiva). Mais do que saber afirmar, o essencial aqui é saber fazer perguntas voltadas para a solução dos problemas, priorizando as perguntas em aberto (que são aquelas que não podem ser respondidas com um não). Correspondem a este tipo perguntas como: 'Por que você quer isso?', 'Por que você acha que isso seria justo?', 'Por que não fazer assim?', 'O que haveria de errado com esta abordagem?’, 'E se atendêssemos a essa exigência...?’ (condicional), 'Qual é o propósito desta política?', 'Como me aconselha a proceder?', 'Quem poderia estabelecer uma exceção?'.

Uma última técnica interessante da metodologia de negociação por princípios é a técnica do texto único, que supõe a mediação. Um mediador elabora um anteprojeto a partir do levantamento dos interesses de ambos os lados da negociação e discute este anteprojeto com cada parte em separado, de maneira alternada, reformulando-o sucessivamente em função das contribuições de cada lado, até que surge uma versão que mais agrade aos dois.

Fisher \& Ertel (1997), interessados na operacionalização prática do enfoque de negociação por princípios, propõem uma verdadeira "caixa de ferramentas para a preparação de uma negociação", que condensa a proposta em termos de formatos e que pode ser muito útil para nós. A partir da mesma, propomos o seguinte protocolo de preparação da negociação:

- Relacionar os atores do nosso lado e do outro afetados com o resultado da negociação.

- Listar, através da técnica ad-hoc, os interesses dos dois lados, procurando priorizá-los. Distinguir os interesses eventualmente comuns e distintos.

- Relacionar padrões “justos” de negociação em torno da questão substancial específica que deve ser respondida nesta negociação (critérios dotados de legitimidade), procurando identificar em que medida podem favorecer ou não nossa posição.

- Identificar algumas opções iniciais de ganho mútuo a partir do exame dos interesses e dos critérios legítimos de negociação.

- Identificar as alternativas dos dois lados, caso nenhum acordo seja conseguido. Ver os prós e contras. Explorar a possibilidade de melhorar minha(s) alternativa(s) e de tornar a(s) do interlocutor menos atraente(s).

- Usar a imparcialidade do processo para persuadir. Neste caso, procurar identificar em que medida processos persuasivos de obtenção de acordos sobre o processo (quando não se chega a um acordo substancial) podem ser aplicados (processos do tipo: eu corto, você escolhe; jogar uma moeda; chamar 
um especialista; deixar um árbitro decidir). E, tentar identificar situações em que o interlocutar se encontra na nossa situação, resgatando seus argumentos e vendo a possibilidade de aplicação na situação concreta (teste de reciprocidade).

- Em relação à comunicação e ao relacionamento:

- listagem dos problemas de relacionamento e das possíveis soluções;

- listagem de nossas suposições acerca das intenções e percepções do outro e do que podemos ouvir (ou do que os outros podem dizer) que possa questionar essas suposições;

- listagem de declarações que nós podemos fazer para expressar nossos interesses e de respostas possíveis da contraparte, visando reenquadrar ou redeclarar nossos interesses de modo que eles os ouçam melhor.

- Simular a situação em termos de um teatro lúdico de negociação, quantas vezes seja necessário, distribuindo os papéis (usar os elementos acumulados analiticamente).

- Listar conclusivamente no mínimo três opções consideradas de ganho mútuo.

\section{Comunicação, Criatividade e Exercício da Influência}

O modelo lingüístico da gramática transformacional de Chomsky (1965) supõe que, entre a representação sensorial primária da experiência e a representação lingüística, operam três formas de modelagem universal (filtros): a generalização, a distorção e a omissão. A generalização consiste em absolutizar uma experiência singular. A omissão é uma forma de negação da experiência, de silenciamento. A distorção é uma nova disposição ou uma nova organização dada aos conceitos, idéias ou objetos. É uma forma de substituição de dados sensoriais. Este metamodelo assume que esses universais operam normalmente na realidade (até mesmo como formas de adaptação e de defesa dos seres), mas que podem assumir contornos patológicos ou gerar situações patológicas (quando se tornam muito persistentes ou se aplicam a contextos inapropriados).

Para o autor, as expressões lingüísticas refletem esses universais da modelagem experiencial. Por exemplo, há pessoas que utilizam muitos operadores modais de possibilidade ou de necessidade. São expressões do tipo: 'é impossível que', 'não posso fazer tal coisa'; 'não é capaz de...' (de possibilidade) ou 'é necessário...'; 'temos de fazer' (de necessidade) etc. São expressões que indicam um limite ou uma impossibilidade, mas não dão informações precisas sobre como 
opera este limite. Na prática, denotam uma extrema rigidez e crenças arraigadas. Os operadores modais se enquadram na classe das omissões. Exemplos de generalizações são as expressões que se utilizam de quantificadores universais do tipo: 'nunca', 'todos', 'ninguém' etc., ou aquelas sem índice referencial como 'não quiseram me deixar falar'. As relações de causa-efeito são consideradas formas de distorção, pois neste caso comete-se, em geral, a inexatidão de atribuir uma única causa a um efeito, assim como as nominalizações que transformam algo dinâmico em um dado fixo, absoluto. A taxonomia geral é bem mais abrangente; o objetivo aqui é apenas dar alguns exemplos.

A idéia implícita é que as expressões lingüísticas configuram uma forma de linguagem superficial que não dá conta do contexto global das representações de base - que correspondem a um nível mais profundo da linguagem. Se eu digo 'João comprou um carro', trata-se de uma estrutura superficial; a estrutura profunda correspondente poderia ser: 'João o comprou de alguém, em tal dia, em tal lugar, um carro de tal marca por determinada quantia'. Assim, a estrutura profunda compreenderia os elementos lingüísticos que representam a experiência, não necessariamente todos, porque os universais de modelagem interviriam uma primeira vez entre a experiência e a estrutura profunda da linguagem, e uma segunda vez entre esta última e a estrutura superficial. Em uma situação patológica, uma eventual tarefa terapêutica consistiria em chegar aos níveis mais profundos, religando o paciente à experiência negada, distorcida ou generalizada, de modo a ampliar suas possibilidades. Pressupõe-se, no caso, que o uso sistemático de expressões classificáveis nos universais de modelagem limitam o modelo de mundo dos seres humanos.

Comunicadores afetos a escolas da psicologia comportamental (Bandler \& Grinder, 1981) apresentam um modelo de questionamento simples (modelo de precisão) que ajudaria a "aprofundar" a linguagem, a diminuir a ambigüidade virtual. Por exemplo:

- no caso da utilização de operadores modais, duas perguntas seriam pertinentes: ‘o que o impede de... ?' (quando a afirmação é: 'não posso fazer tal coisa'); 'o que aconteceria se não ocorresse $X$ ?' (no caso da afirmação: 'devo fazer tal coisa').

- no caso da utilização excessiva de quantificadores universais, do tipo 'ninguém me compreende', pode-se utilizar, em tom interrogativo, o quantificador universal: 'ninguém?' ou exagerar a afirmação acrescentando a ela outro quantificador universal ou inclusive o termo 'é verdade’?

- $\quad$ em relação a expressões sem índice referencial, como já citada, pode ser utilizada a interrogação: 'quem'?

- em relação à utilização de vínculos de causa-efeito do tipo: 'eu sairia de férias, mas não tenho carro', a conexão poderia ser questionada, virando a 
afirmação da seguinte forma: 'Ou seja, se você tivesse um carro, sairia de férias?’; a modificação da forma da afirmação permitiria verificar a existência do vínculo ou deixar aberta a possibilidade de uma réplica (outras formas específicas de enfraquecer vínculos deste tipo serão apresentadas mais adiante).

- quando da utilização de nominalizações, como por exemplo: 'eu tenho esperança', usar: 'o que você espera?', ou 'a dor me esmaga', usar: 'como especificamente ela te esmaga?' (as perguntas o quê? ou como? tencionariam transformar substantivos abstratos em dimensões de processo).

Considera-se, portanto, que a linguagem apresenta "zonas de sombras" que seria preciso iluminar através de um questionamento efetivo e oportuno. Isto corresponde à busca de uma "objetivização" da linguagem que facilite o entendimento dos predicados, que ajude à compreensão do que se formula, que permita um maior esclarecimento do que o outro diz. É a busca por um falar verdadeiro.

Mas considerando-se a criatividade e o exercício da influência, o uso deliberado da linguagem "com zonas de sombra", da linguagem vaga, de enunciados ad-hoc seria paradoxalmente aconselhável, por considerar-se que essa forma exige do ouvinte que ele ative a própria vivência interna, na medida em que, nas deliberações feitas, estão ausentes quase todas as informações específicas. Dito de outra forma, a linguagem vaga estimula a imaginação do ouvinte, contribui para desencadear um movimento interno no sentido da busca de respostas ou de expressões mais precisas e concretas. $\mathrm{O}$ uso de nominalizações ajudaria no exercício da criatividade e da expansão de possibilidades. Este falar vago teria, isso sim, d deslizar rapidamente para um tipo de falar verdadeiro, para resgatar o conteúdo preciso dos produtos da imaginação (Cudicio, 1992). O falar vago e outras formas, apontadas a seguir, correspondem à utilização invertida do metamodelo lingüístico, ao denominado modelo Milton, alusão ao americano Milton Erickson, talvez o maior psiquiatra hipnotista da época moderna.

A linguagem de modelo Milton comporta inúmeras possibilidades (Bandler \& Grinder;1981), como, por exemplo:

- A utilização principalmente de nominalizações, que se prestam a uma diversidade de conteúdos subjetivos, possibilitando despertar a criatividade do interlocutor.

- O uso de pressuposições do tipo 'não sei qual dos dois aparelhos vai comprar' (a suposição é a da compra), consideradas um dos mais poderosos padrões lingüísticos quando empregados por um comunicador que pressupõe aquilo que não quer que seja questionado. Um princípio geral é apresentar à pessoa muitas e muitas alternativas de escolha sendo que, apesar disso, todas elas pressupõem a resposta que você deseja. 
- O uso de vínculos de causa-efeito do tipo 'enquanto duvidamos, nossos concorrentes começam a ocupar pontos estratégicos’ (este é um vínculo propiciado pelo conectivo 'enquanto'). Nestes casos, o comunicador procura ligar algo que está ocorrendo com algo que ele quer que ocorra, convidando o ouvinte a responder como se uma das coisas fosse na realidade a 'causa' da outra. Estes vínculos se apóiam na tendência reconfortante que as pessoas têm de fazer associações, de atribuir uma causalidade tranqüila, acrítica a determinadas coisas (sobre tudo quando uma parte da sentença é um fato que ocorre na realidade). Uma interpretação possível da sentença anterior pode ser a de um chamamento para evitar a indefinição, a divisão, como causa possível da perda de posições.

- A possibilidade de ordens embutidas. Ao invés de dar abertamente as instruções, o comunicador embute diretivas dentro de uma estrutura mais ampla da sentença, que pode ser uma estória. Esta técnica pode ser reforçada pela "marcação análoga" que consiste em dar ênfase a determinadas partes da frase com a ajuda de comportamentos não-verbais (pausas, entonações, gestos, qualidade da voz etc.) para estimular a atenção consciente e inconsciente do ouvinte.

- A utilização de citações de outras pessoas para apresentar indiretamente mensagens, assim como de metáforas, inscrevem-se como outros recursos que ajudam a diminuir ou a quebrar resistências eventuais do ouvinte, que colaboram para a veiculação de conteúdos. Elaborar uma metáfora implica construir um texto que tenha uma estrutura isomórfica em relação à situação de base, mas cujo desenlace se modifica no sentido em que se pretende transitar.

Citamos apenas estas possibilidades no intuito de ilustrar como a técnica da comunicação hipnótica pode ser explorada no campo da persuasão. Podemos enriquecer esta narrativa citando algumas outras alternativas também muito úteis:

- O uso de ordens negativas em pessoas resistentes ou responsivas no sentido inverso daquele em que são instruídas. Exemplo: 'não quero que você tenha uma sensação de relaxamento e conforto'. Uma resposta de polaridade pode ser o efetivo relaxamento.

- Evitar, no caso de pessoas rígidas e contraditórias, a utilização exagerada do 'sim, mas ...' e dos contra-exemplos, pois isto pode contribuir para reforçar uma dada posição. Seria melhor seguir a corrente do ouvinte, exagerando ou enfatizando propositalmente a problemática ou a posição do mesmo, que neste caso, o próprio ouvinte poderá dar os contra-exemplos necessários à reformulação de uma dada posição que insista em manter. Reagirá assim com uma alternativa de polaridade. 
- Anunciar as conseqüências negativas de um não acordo caminha na direção daquela tendência natural - já citada - de fugir do desagradável, podendo abrir espaço para possibilidades de acordo.

- A modificação proposital do sistema de representação consciente do outro (implícita, por exemplo, nas técnicas de dissociação) criaria estados alterados de consciência, que são estados que se caracterizam por uma menor resistência à possibilidade de novos aprendizados, de uma mudança.

- A interrupção brusca (através de recursos vários) de padrões arraigados de comportamento do outro comportaria a mesma lógica anterior e é um dos recursos mais importantes dos processos de indução hipnótica. Interromper repentinamente uma "lenga-lenga" é uma interrupção de padrão que gera um estado alterado de consciência, de confusão, que pode ser explorado para efeitos de produção de novos significados.

Finalizaremos esta parte fazendo referência a alguns meios de influência citados por Cudicio (1992) cuja finalidade seria quebrantar ou questionar relações de causa-efeito implícitas nos enunciados do outro. Estas técnicas pretendem reorientar a discussão na direção de novas opções diante de uma afirmação peremptória que reflete o beco sem saída a que chegou um conflito. Serviriam, portanto, para manejar o conflito de maneira criativa e para influir sobre os outros (podendo levar à modificações de opiniões).

Vejamos um exemplo: 'Você sempre chega atrasado, isto demonstra sua falta de interesse no trabalho.' É um vínculo de causa-efeito e de igualdade. O critério implícito é a pontualidade, para o autor da afirmação.

Diante de afirmações desta natureza, o "cardápio da influência" contém genericamente três alternativas: deslocar, evitar ou dar contra-exemplos. Vejamos algumas possibilidades:

\section{Alargar ou comprimir o debate}

\section{Alargar}

A técnica consiste em alargar indo para níveis lógicos superiores. Se falássemos de um gato, poderíamos alargar passando para a categoria felino, depois mamífero, depois animal. Uma possível resposta seria: "Que significa 'chegar tarde', considerando que a empresa dispõe de toda a minha vida ativa futura?". 


\section{Comprimir}

Inversamente, agora podemos ir para níveis lógicos inferiores: 'só me atrasei exatamente 10 minutos'.

\section{Utilizar a hierarquia de critérios}

A técnica consiste em acrescentar critérios cada vez mais importantes: 'Para mim, o mais importante é a produtividade efetiva, não a demora’.

\section{Modificar o marco do debate}

Trata-se de modificar o marco, isto é o contexto. Podemos modificar seu tamanho, sua duração ou quaisquer elementos. Por exemplo: 'parece que você não soube o que aconteceu hoje'; ou: 'o que te faz saber que meu atraso tem a ver com um estado de ânimo?'.

\section{Os contra-exemplos}

É o 'sim, mas...', útil também no caso das pressuposições. Exemplos: 'Se você costumasse chegar tarde, isto significaria que você não se importa com o trabalho', ou 'Fulano de tal sempre chegava tarde, mas sua dedicação e a sua produção desmentiam críticas como a sua.'

\section{Refutar}

É possível refutar o comportamento exterior, o critério ou a causa-efeito.

- O comportamento: 'Você não percebe, mas, na verdade, eu me importo'.

- O critério: 'Então, o que conta para você é a hora? Em que me transformei aqui dentro? Meu rendimento não interessa?'

- A causa-efeito: 'se não eu chegasse tarde, você acreditaria que me importo com o trabalho?' 


\section{Reformular, redefinir}

Pode-se reformular a frase mas na forma de uma interrogação ou redefinila para verificar sua exatidão. Quando afirmamos algo de má-fé dificilmente conseguimos repetir pela segunda vez a afirmação com a mesma convicção. Exemplo: 'se entendi bem, o fato de chegar atrasado significa que não me importo com o trabalho?'

\section{A estratégia de realidade}

Este traço distintivo coloca a seguinte pergunta: Como sabe uma pessoa o que sabe, e de que elementos necessita para verificar sua experiência? Exemplo: 'Como você pode saber que não me importo com o nosso trabalho?'

\section{O objetivo}

Interrogamos sobre o objetivo da pessoa ou de sua afirmação. Exemplo: 'O que você ganha perguntando isto?'; 'O que você pretende fazer para solucionar o problema?'.

E assim por diante, trata-se de um conjunto de técnicas simples de influência que buscam desviar a atenção do problema ou o foco de concentração do outro, deslocar o nível de análise envolvido ou arrolar argumentos contrários a determinadas afirmações. Desta maneira, presume-se atingir uma situação de amenização de conflitos ou demover outros de suas posições.

Sobre um provável sentido manipulador destas técnicas, poderia-se afirmar que nenhuma técnica é neutra, dependendo de quem as utiliza. E que, assim como elas podem ser utilizadas para induzir posições nos outros, podem também ajudar a detectar esta intenção nos interlocutores e a desarmá-la. Podem ajudar, ainda, a modificar posições tidas como equívocas, negativas. Em relação, agora, ao falar vago, deve-se salientar que esta forma não pode ser absolutizada, pressupondo uma derivação permanente para o falar verdadeiro, e que, nesse caso, não se trata da transmissão de mensagens específicas, mas de generalizações que podem intensificar a geração de idéias novas e variadas, de utilidade para a negociação. Dito de outra maneira, nenhuma mensagem contrária ao ponto de vista do interlocutor é transferida; a resposta está no próprio ouvinte. O importante é resgatar que uma estratégia inteligente de combinação de falares deve estar subordinada à busca de um entendimento duradouro, que não signifique a negação absoluta de nenhuma da partes do jogo. 


\section{Considerações Finais}

Buscamos, aqui, apresentar a idéia de que a negociação é um processo de criatividade e de comunicação intensiva. A questão central é conseguir gerar a máxima quantidade de idéias ou opções capazes de ensejar acordos de alcance variado, para além da busca de uma única forma ou da fixação em um único tipo de resposta.

O modelo de negociação é altamente desestruturado, de difícil planejamento e controle. Depende das situações em jogo, dos tipos de negociador e de inúmeras variáveis subjetivas e objetivas. Mas um esforço pode ser feito no sentido de um planejamento mínimo, cujo objetivo seja o de chegar à negociação com alternativas.

Procuramos, no desenvolvimento da apresentação do modelo cooperativo, ajudar a instrumentalizar gerentes no exercício do mesmo, convictos de que, apesar da dinamicidade da negociação, o que significa assumir várias formas entrelaçadas e evolutivas, a possibilidade de um acordo duradouro, superior, insere-se na perspectiva do ganhar-ganhar.

Planejamento da negociação significa um mínimo de antevisão de possibilidades. Pode-se simulá-las mais facilmente utilizando um roteiro como o que apresentamos no Anexo, cujo único objetivo é gerar informação que pode ser útil, de acordo com cada caso real.

Terminamos aqui reafirmando a necessidade de um enfoque pragmático que combine argumentação e persuasão, esta última subordinada. Idealizamos, no entanto, um enfoque argumentativo, em que o livre e irrestrito exercício da comunicação crítica seja a tônica. Não deixa de ser uma boa causa.

\section{Referências Bibliográficas}

BANDLER, R. \& GRINDER, J. Atravessando. Passagens em Psicoterapia. São Paulo: Summus, 1981. (anexo final sobre o modelo Milton).

CHALVIN, D. LEntreprise Négociatrice. Paris: Dunod, 1997.

CHOMSKY, N. Aspects of the Theory of Sintax. Cambridge: MIT Press, 1965.

CUDÍCIO, C. Cómo Compreender la P.N.L. Introducción a la Programación Neurolinguística. Argentina: Granica, 1992. (Série Alternativa Management)

FISHER, R. \& URY, W. Como Chegar ao Sim. A Negociação de Acordos sem Concessões. Rio de Janeiro: Imago, 1982. 
FISHER, R. \& BROWN, S. Como Chegar a um Acordo. A construção do relacionamento que leva ao sim. Porto Alegre: Imago, 1990.

FISHER,R. \& ERTEL, D. Estratégias de Negociação. Um Guia Passo a Passo para Chegar ao Sucesso em Qualquer Situação. Rio de Janeiro: Ediouro, 1997.

KLUCZNY, J. NLP. Practitioner Training Manual. Seminário NLP in Rio, jan. 1993. (Mimeo.)

MATUS, C. PES. Guia de Análisis Teórico. Fundación Altadir. Venezuela, 1994 (Mimeo.)

MINTZBERG, H. Structure et Dinamique des Organizations. Paris: Les Éditions d'Organization, 1982.

RIVERA, F. J. U. Por um Contraponto Teórico-metodológico entre o Planejamento Estratégico-Situacional (PES) e o Controle da Qualidade Total (T.Q.C.) na Saúde Pública.. Rio de Janeiro, ENSP/Fiocruz, 1995. (Mimeo.)

URY, W. L.Supere o Não. Negociando com Pessoas Dificieis. São Paulo: Best-Seller, 1991.

ZAJDSZNAJDER, L. Teoria e Prática da Negociação - Política de Negociação. Rio de Janeiro: José Olympio, 1988.

ZAPIOLA, C. La Negociación. Un Enfoque Integral con Especificas Referencias a la Negociación Laboral. Bogotá: Ed. Macchi, 1992. 